\title{
Resilience in Children: The Nature and the Importance of the Concept ${ }^{1}$
}

\author{
Emory L. Cowen e Peter A. Wyman \\ University of Roches/er

\section{Summary} \\ Considers the meaning of the term childhood resilience and the importance ofits place in the fields of \\ developmental psychopathology and wellness enhancement. Reviews several major longitudinal research \\ projects on childhood resilience that have contributed significantly to the field's emergence and presents more \\ detailed information on the Rochester Child Resilience Project (RCRP). A final section summarizes \\ accomplishments in resilience research to date, and identifies needed foci for future work in this area.
}

Key words: Child resilience; development; personality.

\section{Resiliência em Crianças: natureza e importância do conceito}

\begin{abstract}
Resumo
Considera o significado do termo resiliência na infância e a importância de seu lugar no campo da psicopatologia de desenvolvimento e construção do bem-estar. Revisa os principais projetos de pesquisa longitudinais em resiliência na infância que contribuíram significantemente para a emergência do campo e apresenta informações detalhadas sobre o Projeto de Rochester (RCRP). Uma sessão final sumariza compromissos da pesquisa em resiliência e identifica necessidades para futuros trabalhos na área.
\end{abstract}

Palavras chaves: Resiliência; desenvolvimento; personalidade.

Interest in the concept of childhood resilience, and research bearing on this topic, have grown rapidly in recent years. In the sections that follow, we consider several basic facets of this development:

1. What, exactly, does the telw childhood resilience mean?

2. Why is it important to study it?

3. What have major resilience research projects thus far demonstrated?

4. What is the field's current status and some of its more pressing future needs?

\section{Tbe Concept of Cbildbood Resilience}

The term resilience has been used widely both in the scientific and popular literatures, but not always in the same way. Popular usage is looser than scientific usage, often depicting resilience as synonymous with good adjustment. Although scientific-research definitions are more discriminating, they toa reflect some varia ability. Most such definitions highlight two key elements, i.e.: a) good adjllstment; b) in the face of significant life stress (the latter being a risk factor that increases the likelihood maladaptive outcomes) (Garmezy, 1983; Masten \& Coatsworth, 1998), there are imp011ant differences in how good adjustment is viewed within that framework (Kaufman, Cook, Amy, Jones \& Pittinsky, 1994). Whereas some define adjustment as the absence

\footnotetext{
${ }^{1}$ The authors express their sincere gratitude to the W. T. Grant Foundation for its support ofthe work described in this article.
} 
of a diagnosable disorder - a criterion by which $\sim 90 \%$ of the population classifies as well adjusted, others (ourselves included) use a more stringent definition that requires the presence of demonstrably good adjustment. Such a view is consistent both with Wemer and Smith's (1982) description of resilient children as those who "worked well, played well, loved well and expected well" in the face ofmajor life adversity, and our focus (Cowen, 1994; 1996; 1997) on psychological wellness and its enhancement. This real definitional difference can affect the populations that resilience research targets, the methodologies and designs they use, and how research findings are viewed and interpreted. (Cowen, 1997; Kaufman et al., 1994).

\section{The Importance of Studying Resilience}

Despite the preceding definitional fuzziness, widespread agreement about the importance ofthe concept of resilience and the need to better understand it in relation to risk and protective factors have made this topic a central focus for the fields of developmental psychopathology (Cicchetti, 1989; Cicchetti \& Garmezy, 1993; Luthar, Doemberger \& Zigler, 1993; Masten, 1989; Masten, Best \& Garmezy, 1990; Masten \& Coatsworth, 1995) and prevention (Cowen, 1994; Cowen et al., 1996).

The field of developmental psychopathology applies developmental principies to the study of at-risk and deviant children in seeking to identify pathways that relate to good and poor adjustment outcomes. Because the field rests on the assumption that knowledge of normal development can clarify understandings of deviant outcomes and vice versa, the topic of resilience, operationalized by positive adaptive outcomes that run counter to base-rate expectations, falls squarely within its purview (Cicchetti, 1989; Cicchetti \& Cohen, 1995). Relatedly, from prevention's perspective, the case has been made that understanding the nature of, and pathways to, odds-defying resilient outcomes in children (Garmezy, 1983) is a key step in advancing a psychology ofwellness. In that sense, resilience redirects attention from mental health's past focus on the causes of pathology (pathogenesis) and its treatment, toward the enhancement of wellness (Cowen, 1994, 1998). In this context, Antonovsky (1979) proposed the term salltogenesis to direct attention to processes that act to promote wellness outcomes. The point to underscore, however, is that when wellness-enhancing objectives are central, resilience is an especially appealing concept to study.

\section{Major Resilience Research projects}

Two major longitudinal projects, both still ongoing, have helped greatly to stimulate the study of child resilience (including our own work in this area in the past 12 years). The first, Project Competence (Garmezy, Masten \& Tellegen, 1984; Masten, 1989) gathered information from parents about stressors experienced by urban 3rd-6th grade children, and identified predictors of competent outcomes under stressful conditions. Two composite school adjustment factors, (i.e., engaged and disruptive behaviors), were used as focal outcome indicators. Both child and family factors (e.g., levei of child' s cognitive functioning and parental efficacy) were identified that related to competent outcomes in the face of major stress and moderated relationships between exposure to stress and resilient outcomes. A recent comprehensive review reflecting in pm1 the experiences and findings of Project Competence addressed the challenging question of competent development under favorable and unfavorable conditions (Masten \& Coatsworth, 1998).

The Kauai Longitudinal Study, a second major study of child resilience, is now four decades 
old (Werner, Bierman \& French, 1971; Werner \& Smith, 1977; 1982; 1992). This unique, doggedly persistent venture has carefully followed the full cohort ( $\mathrm{n} 700)$ of children born on the Hawaiian island of Kauai in 1955. Ear1y assessments identified some 200 youngsters $(28 \%)$ in this group who showed $\geq 4$ or more significant risk factors (e.g., bitlh complications, family poverty) by age 2 . First seen for annual well-baby and pediatric exams, the sample has been followed via periodic testing, interviews and examination of record data in order to monitor participants' physical and psychological well-being.

Among the study's most striking early findings was that 70 of the 200 high-risk youngsters exposed to multiple, profound early life stress had "remained invincible and develo ped into competent, autonomous adults," as of age 18 (Werner \& Smith, 1982, p. 13). These youth were much better adjusted than their stress-affected peers on a broad range of wellness indicators including bellwether ones such as school performance, and work, and arrest records. Since then, the Kauai study has continued to assess outcome differences between initially classified stress-affected and resilient children and to identify variables that favor resilient outcomes under stressful life conditions. The latter include: child-qualities (i.e. an easy infant temperament, autonomy and social competence as toddlers, scholastic competence in middle childhood and good self-esteem) and parental factors (i.e. parenting competence, sound caregiving practices and discipline styles and support, all embedded in the context of a wholesome parent-child relationship according to Werner \& Smith, 1992).

In addition to these, two high-impact projects, several others also have contributed importantly to the resilience literature. The Kaiser-Permanente longitudinal study (O'Grady \& Metz, 1987) which tracked outcomes at ages 6 to 7 of 84 children first studied and classified as high-risk, at age one month. And studies of competent or resilient outcomes among highly stressed adolescents, and "costs" (e.g., heightened anxiety) that some believe to be associated with such outcomes (Luthar, 1991; 1999; Luthar, et aI., 1993).

The resilience research cited has been done with children and youth who vary in age, sociodemographic attributes, and the nature of risk factors experienced. It is also based on substantially different study designs and measures. Such differences notwithstanding, important cross-study convergence in findings have emerged identifying a triad of protective factors that favor resilient outcomes under stressful life circumstances. These include an easy temperament early in a child's life; a warm, caring, secure family environment; and the availability of wholesome identification models, with whom to identify outside the family (e.g. teachers and clergypersons) (Garmezy, 1983; Werner \& Smith, 1982).

\section{The Rochester Child Resilience project (RCRP)}

The Rochester Child Resilience Project (RCRP), cast in the context ofthe preceding research, involves four major interrelated studies. The first two are cross sectional and the last two are longitudinal. All studies have focused on poor, predominantly (55-75\%) racial-ethnic minority, urban children, with histories of heavy stress exposure. Results from the first three studies are known; the fourth began only recently. Only highlights of this research are presented here; original data sources are cited for those seeking for more detailed knowledge.

The RCRP's initial goals, reflected in its first two studies, were to identify corre lates and antecedents of resilient outcomes among highly stressed children. These two multiyear studies were 
done with 9 to 11 , and 7 to 8 year old children and their families, respectively. Although the two studies were not identical, they had important common features. Those included a common method for identifying stress affected (SA) and stress-resilient (SR) children, based on the following criteria: a) having experienced $\geq 4$ major stressful life events (e.g., chronic family arguments, being in foster care, exposure to violence) as reported by the parent. In samples thus far studied, the average number of stressors has been 9 ; b) independent categorizations by parents, and current and prior year teachers placing youngsters in the top (SR), or bottom (SA), third in adjustment; and c) verification of this consensual placement via in-depth adjustment ratings of current teachers. Thus, although all RCRP children shared the common risk factor of exposure to major life stress, SRs and SAs differed sharply in terms of whether informed observers judged them to be well, or poorly, adjusted. Consistent with our emphasis on positive adaptive criteria, SR children were significantly better adjusted than demographically matched, non-stress-exposed peers (Cowen, et al., 1992).

Important differences between the two studies included: a) using fewer items and simplified item wordings and rating metrics on Study 2 test measures, consistent with the more limited cognitive capacities and attention spans of younger children; and b) casting the second study, from the start, into a longitudinal framework that provides a gateway to Studies 3 and 4 (cf. below). Before coming to the latter, however, we describe briefly how the first two RCRP studies were actually done and what they found.

The first study (4th-6th graders) rested on a mini-conceptual model for resilience developed by Cowen and Work (1988). Conducted over a 2-year period, the study was based on three sets of data: child testing (Cowen et al, 1992; Parker, Cowen, Work \& Wyman, 1990); child interviews (Wyman et al., 1992) and parent interviews (Wyman, Cowen, W ork \& Parker, 1991). The eleven measures used in the child test battery, included self-rating of adjustment, perceived competence, empathy, locus of control, realistic control attributions, coping styles, social problem-solving, anxiety, depression and perceived support (Cowen et al., 1992; Parker et aI., 1990). All children later were interviewed individually, in school, for about 1 hour to obtain information in areas that lacked formal test measures (Wyman et al., 1992). A comprehensive, 2 1/4 hour parent interview, with 35 open-ended and 244 objective items provided information on family background, developmental milestones during infancy, preschool, and school-age periods; discipline practices, parent resources, and views ofthe child's future (Wyman et aI., 1991).

Principal findings follow: SRs exceeded SAs on self-rated adjustment, perceived competence, empathy, intemality of locus of control and realistic control attributions, as well as social problem solving, coping skills and support available from relatives and friends. Five variables sensitively discriminated SRs and SAs, and classified participants with $84 \%$ accuracy (i.e., empathy, global self-worth, social problem solving, realistic control attributions, and selfesteem) (Parker et al., 1990). Child interviews identified other important group discriminators, (e.g., the child's sense of efficacy, having positive future expectations and a positive view of the parent-child relationship).

Findings from the parent interview added depth to this picture. Several predictors of SR outcomes were identified from each developmental period. During infancy, childrearing support from a father figure and others, nonseparation of caregiver and child, an easy temperament, and early achievement of developmental milestones. Significant predictors during the preschool period again included an easy temperament as well as a sound parentchild relationship. The latter, along 
with the caregiver's sense of efficacy, predicted SR outcomes during the school-age period. Other sensitive predictors included consistent, authoritative, age-appropriate parent discipline; optimism about the child's future; and the parent's having a positive self-concept, good support sources, and a strong sense of life satisfaction. Seven parent variables correctly classified $86 \%$ ofthe sample as SR or SA. During infancy, few separations of caregiver, an easy child temperament, and contributions to child care by a father figure and others, discriminate SR from SA. The use of consistent, ageappropriate, sound discipline practices and positive expectations for the child's future also discriminate both conditions (Wyman et aI., 1991).

Both parent and child interview findings underscored the importance of a wholesome parentchild relationship (e.g., warrn, caring parental attitudes; involvement in joint activities with the child; and sound parent discipline practices) in favoring SR outcomes in this highly stressed sample (Gribble et ai, 1993). Also SR, compared to SA, parent-child dyads had more congruent views of the parent-child relationship and of their own expressive-motor styles (Cowen, W ork \& Wyman, 1993). A three year follow-up of this sample, upon their entry at high identified two additional findings. First, children's positive future expectations in middle childhood predicted better adjustment three years later and moderated the negative effects of intervening stress on perceived competence (Wyman et al., 1993). Second, high initial scores on global self-worth and reading achievement predicted low risk for later drug and alcohol use, and heavy exposure to recent stress predicted higher risk for substance abuse (Wyman et aI., submitted). These findings generally suggest knowledge of a child's adaptive status (SR vs. SA) at ages 10 to 12 provides a reasonable basis for predicting important aspects of adolescent functioning 2 to 3 years later.

The second major RCRP study was a downward extension of the previously described study and focused on highly stressed 7 to 8 year old urban children. Although the two studies were similar structurally (e.g., group selection procedures) they also differed in important ways. The second study was designed as a longitudinal study. Second, modest changes were made in the nature of data acquired from children and their parent (Hoyt-Meyers et al., 1995; Wyman et al., 1999). Several measures that were toa advanced cognitively for 7 to 8 year olds were dropped and other measures that reflected the developmental level of these youngsters used. Non-discriminating items from the prior parent interviews were dropped and new questions added in several domains (e.g., parenting attitudes, parents' own childhood experiences).

In this study, SR and SA groups, matched sociodemographically and for stressors experienced, were drawn from a pool of 759 consenting families. The modified test battery included 8 measures. These included a measure of intelligence, report of adjustment and anxiety, self-efficacy, perceived competence, realistic control attributions, social problem solving and empathy (HoytMeyers et al., 1995). Most measures were administered in small group sessions. Three to eight weeks later the WISC (Vocabulary and Block Design), perceived competence, and social problemsolving measures were administrated. Results were similar to those from Study 1, though somewhat less robust. Specifically, SRs exceeded SAs in self-rated adjustment, perceived competence, intelligence, realistic contrai, empathy and social problem-solving. Four predictors (i.e. self-rated mIe compliance, intelligence, Harter Behavioral Conduct and Physical Appearance) correctly classified $80 \%$ ofthe sample as SR or SA..

Parents of SR, compared to SA, children repolied that their offspring had easier temperaments in infancy and early childhood, and had achieved developmental milestones sooner. They 
also reported more positive relationships, and sounder, more consistent discipline practices with their children, had a more positive outlook about their child's future, and exceeded SA parents in support available, self-concept, and global mental health in the past year. They had fewer negative child-rearing attitudes (e.g., inappropriate expectations, role reversal) and practices, and their childrearing behaviors were influenced by more positively caregiving experiences during their own childhood (Wyman et ai, 1999).

Interviewers blind to parents' group status correctly classified $80 \%$ as parents of SR or SA children. Seven parent variables correctly classified $75 \%$ of the sample: positive parent views of and future expectations for the child; few negative child-rearing attitudes; the influence ofthe parents' own childhood on parenting; use of sound discipline practices, and the presence of an easy child temperament in infancy, and a warm parent-child relationship in the preschool period. Impoliantly, support was found for the hypothesis that responsive parenting attitudes and behaviors predicted resilience and that the effects of other contextual resources (e.g. parent education and mental health) on children's adjustment were mediated through parenting quality. These findings underscore the protective value of a sound parent-child relationship, positive child rearing and discipline practices, and the parent's own competencies and resources as key factors that favor SR outcomes among children who grow up under chronically stressful conditions. (Wyman et ai, 1999)

First Follow-up - One and one-half to two years after the initial (TI) evaluation a follow up (T2) evaluation was conducted, including child testing and parent interviews. Notwithstanding high mobility rates, about $90 \%$ of the initial sample was located and agreed to participate in the followup study (Cowen et al., 1997). At that time, parents and teachers rated child adjustment using the same measures used at $\mathrm{T} 1$ and the children retook tive ofthe $\mathrm{T} 1$ measures.

The following were among the study's main findings: Parents and the new (T2) teachers again rated SRs as better adjusted than SAs. SRs continued to exceed SAs on adjustment, perceived competence, empathy, social problem solving and realistic contraI. Four variables (i.e., rule conformity, perceived self-worth, social problem solving, and realistic control) correctly classified $75 \%$ ofthe sample as SR or SA. Median test-retest rs of.35 for the common T1 and T2 child measures, and .46 for the T1 and T2 parent and teacher adjustment ratings suggest moderate shortterm stability in children's initial adjustment status (Cowen et ai, 1997).

The T2 parent interview included some repeat questions from TI (e.g., sense of efficacy as a parent, support sources) and several new items to assess parent coping strategies, predelinquent indicators in the child (Yoshikawa, 1994) and changes in the family situation between T1 and T2. Parents of SRs again exceeded parents of SAs in their positive of views of parent-child relationship, judged efficacy as a parent, and on self-esteem, support received, and global mental health during the T1 - T2 interval. They also used more adaptive coping styles, reported fewer delinquent behaviors in their offspring, and had more positive future expectations for them.

Interviewers rated SR parents more positively than SA parents. Fourvariables correctly classified $78 \%$ of the sample: positive future expectations for the child, few predelinquent indicators, parent use of effective coping strategies, and good parental mental health. The median test-retest $r$ of .53 found between the 17 variables common to the T1 and T2 interviews again indicated reasonable short-term stability in such views.

Currentfollow-up - Data collection (i.e., youth testing and interviews, and parent interviews) is now in progress on a longer term follow-up ofthese same participants, first studied between 1991- 
1993, and followed up two years later (cf. above). Now young adolescents, each ofthe two yearcohorts will be evaluated twice, separated by 2 years, first as 13-14 year olds at the time of high school entry (T3), and again two years later as high schooljuniors (T4). Data collection at each point will include a 15-measure youth test battery, as well as extensive youth and parent interviews. Some measures used, with age-relevant items and format modifications, will parallel earlier assessment procedures. Other, new ones will be introduced to reflect criteria and outcomes of importance in adolescence, as for example indicators of: trust/intimacy; exposure to crime and violence; delinquency and anti-social behaviors of self and friends; use of alcohol and drugs; and health behaviors.

The questions that frame the new followup study include:

1. How stable are the initial adjustment classifications made 6-7 years earlier?

2. Which initial, and/or early follow-up, factors predict stability or change (both upward or downward) in initial adjustment status?

3. What pathways underlie adjustment maintenance, gain, and erosion?

4. To what extent do answers to the preceding questions vary as a function of youth gender and ethnic status?

Ofthe 199 families evaluated at T1, 181 were again evaluated at T2, 2 years later. We hope now, seven years later, to locate, gain consent, and complete testing and interviewing with at least 150 of these youth and their principal caregivers. One obstacle in this quest is the sample's high mobility rate both within the local geographic area and around the country. Additionally, untoward life events, (e.g., mother in jail or a mental institution), realistically restrict access to some families. In the Year 1 follow-up sample ( $\mathrm{n}=109$ ), we have thus far located and evaluated roughly 90 youth and caregivers, ofwhom 10 were in school districts $\geq 80 \mathrm{~km}$ from Rochester. In the latter cases, individualized arrangements were worked out for youth testing and interviews and for compiling relevant school record information. The information thus far gathered seems to be of substantial interest and impOliance. Hence, we plan to pursue the goal of locating and evaluating as many as possible ofthis special sample, at two critical points in their adolescent development.

\section{Future Directions}

Recent research has provided considerable information on nature of child resilience and its central place in the fields of developmental psychopathology and prevention-wellness enhancement. Future research may take at least three directions. One is to extend knowledge about the corre lates and antecedents of resilient outcomes under stressful conditions by identitying the roles of other conceptually pertinent but not yet studied variables (e.g., intrinsic motivation, growing up in autonomy supportive contexts). Additional pathways that enable some children to cope effectively with major life stress, while others, exposed to comparably serious stress, founder maladaptively need to be identified. Emerging statistical technologies (e.g. path analysis, structural equation modeling and hierarchicallinear modeling) provide analytic tools that may facilitate moving beyond prior cross-sectional foci on outcome corre lates to a longitudinal, process-oriented levei that may lead to a richer understanding of the evolutionary dynamics of resilient outcomes.

Developments in the two preceding areas set the stage for a third set of data-based steps: articulating informed, multi-level, preventively-oriented, building approaches that inoculate against stress, and work toward wellness from the start, by enhancing the adaptive capacities of young 
stress-exposed children. RCRP research to date strongly suggests that effective resilience enhancing interventions for children exposed to chronic stress are likely to be ones that are launched early in the child's development, are directed to family units, particularly primary caregivers who play crucial roles in the child's formation (Masten \& Coatsworth, 1998; Wyman et aI., 1991; 1999), and include "booster shots" and new inputs reflecting the child's growing maturity and cognitive capacities. Ofinterest in this context is the convergent conclusion of three recent reviews of delinquency prevention programs (Tolan \& Guerra, 1994; Yoshikawa, 1994; Zigler, Taussig \& Black, 1992) that an early start and a family focus are crucial elements in interventions that work to prevent delinquency.

Energetic study of child resilience under stressfullife conditions has both yielded major immediate dividends and pointed the way toward needed future research. Resilience, as noted, is an important focus both for developmental psychopathology and preventionwellness approaches. One especially appealing aspect ofthis focus is the unusual opportunity it offers for combining rigorous scientific inquiry with much needed practical applications. That special combination holds potential for direct benefit to many children in need, and ultimately to society at large.

\section{References}

Antonovsky, A. (1979). Health. stress and coping.San Francisco: Jossey-Bass.

Cicchetti, D. (1989). Developmental psychopathology: Some thoughts on its evolution. Development and Psychopathology, I, 1-4.

Cicchetti, D. \& Cohen, D. 1. (1995). Perspectives on developmental psychology. Em: D. Cicchetti \& D. J. Cohen (Eds.), Developmental psycho pathology: Theory and methods Vol. 1 (3-20). New Y ork: Wiley-Interscience.

Cicchetti, D. \& Garmezy, N. (1993). Milestones in the development ofresilience. Development and Psychopathology, 4,497-783.

Cowen, E. L. (1994). The enhancement of psychological wellness: Challenges and opportunities. American Journal of Community Psychology, 22, 149-179.

Cowen, E. L. (1996). The ontogenesis of primary prevention: Lengthy strides and stubbed toes. American Journal of Community Psychology, 24,235-249.

Cowen, E. L. (1997). Schools and the enhancement of psychological wellness: Some opportunities and some limiting factors. Em: T. P. Gullotta, R. P. Weissberg, R. L. Hampton, B. A. Ryan, \& G. R. Adams (Eds.), Healthy children 2010: Establishing preventive services (97-123). Thousand Oaks, CA: Sage Publications.

Cowen, E. L. (1998). ln sickness and in health: Primary prevention's vows revisited. Em: D. Cicchetti \& S. L. Toth (Eds.), Rochester Symposium on Developmental Psychopathology, V 01. 10 Rochester, NY: University ofRochester Press.

Cowen, E. L.; Hightower, A. D.; Pedro-Carroll, 1. L.; Work, W. c.; Wyman, P. A. \& Haffey, W. G. (1996). School based prevention for children at risk: The Primary Mental Health Project. Washington, DC: American Psychological Association. 
Cowen, E. L. \& Work, W. C. (1988). Resilient children, psychological wellness and primary prevention. American Journal of Community Psychology, 16, 591-607.

Cowen, E. L.; Work, W. C. \& Wyman, P. A. (1993). Similarity of parent and child self-views in stress-affected and stress-resilient urban families. Acta Paedopsychiatrica, 55, 193-197.

Cowen, E. L.; Work, W. c.; Wyman, P. A.; Parker, G.R.; Wannon,M.\&Gribble,P.A. (1992). Test comparisons among stress-affected, stressresilient and nonclassified fomih through sixth grade urban children. Journal of Community Psychology, 20, 200-214.

Cowen, E. L.; Wyman, P. A.; Work, W. C.; Kim, J.; Fagen, D. B. \& Magnus, K. B. (1997). Followup study of young stress affected and stress resilient urban children. Development and Psychopathology, 9, 565-577.

Gannezy, N. (1983). Stressors of childhood. In N. Gannezy \& M. Rutter (Eds.), Stress, coping and development in children (43-84). New York: McGraw Hill.

Garmezy, N.; Masten, A. S. \& Tellegen, A. (1984). The study of stress and competence in children: A building block for developmental psychopathology. Child Development, 55, 97-111.

Gribble, P. A.; Cowen, E. L.; Wyman, P. A.; Work, W. C.; Wannon, M. \& Raoof, A. (1993). Parent and child views of the parent child relationship and resilient outcomes among urban children. Journal ofChild Psychology and Psychiatry, 34, 507-519.

Hoyt-Meyers, L. A.; Cowen, E. L.; Work, W. C.; Wyman, P. A.; Magnus, K. B.; Fagen, D. B. \& Lotyczewski, B. S. (1995). Test correlates of resilient outcomes among highly stressed $2^{\text {nd }}$ and $3^{\text {rd }}$ grade urban children. Journal of Community Psychology, 23, 326-338.

Kaufman, J.; Cook, A.; Arny, L.; Jones, B. \& Pittinsky, T. (1994). Problems defining resiliency: Illustrations from the study ofmaltreated children. Development and Psychopathology, 6, 215229.

Luthar, S. S. (1991). Vulnerability and resilience: A study of high-risk adolescents.Child Development, 62, 600-616.

Luthar, S. S. (1999). Children in poverty: Risk and protective factors in adjustment. Thousand Oaks, CA: Sage Publications.

Luthar, S. S.; Doemberger, C. H. \& Zigler, E. (1993). Resilience is not a unidimensional construct: lnsights from a prospective study of inner-city adolescents. Development and Psychopathology, $5,703-718$.

Masten, A. S. (1989). Resilience in development: Implications of the study of successful adaptation for developmental psychopathology. Em: D. Cicchetti (Ed.), Rochester Symposium on Developmental Psychopathology V 01.1 (261294). Hillsdale, NJ: Erlbaum.

Masten, A. S.; Best, K. M. \& Garmezy, N. (1990). Resilience development: Contributions from the study of children who overcome adversity. Development and Psychopathology, 2, 425-444.

Masten, A. S. \& Coatsworth, J. D. (1995). Competence, resilience and psychopathology. Em: D. Cicchetti \& D. I. Cohen (Eds.), Developmental psychopathology: Risk, disorder and adaptation Vol. 2 (715-752). New York: Wiley. 
Masten, A. S. \& CoatswOlih, J. D. (1998). The development of competence in favorable and unfavorable environments: Lessons from research on successful children. American Psychologist, 53, 205-220.

O'Grady, D. \& Metz, J. R. (1987). Resilience in children at high risk for psychiatric disorder. Journal of Pediatric Psychology, 12,3-23.

Parker, G. R.; Cowen, E. L.; Work, W. C. \& Wyman, P. A. (1990). Test corre lates of stress resilience among urban school children. Journal of Primary Prevention, 11, 19-35.

Tolan, P. H. \& Guerra, N. G. (1994). Prevention of delinquency: Current status and issues. Applied and Preventive Psychology, 3, 251-273.

Wemer, E. E.; Bierman, J. M. \& French, F. E. (1971). The children of Kauai: A longitudinal study fram the prenatal period to age ten. Honolulu: University ofHawaii Press.

Wemer, E. E. \& Smith, R. S. (1977). Kauai's children come of age. Honolulu: University of Hawaii Press.

Wemer, E. E. \& Smith, R. S. (1982). Vulnerable but invincible: A study of resilient children. New Y ork: McGraw-Hill.

Wemer, E. E. \& Smith, R. S. (1992). Overcoming the odds: High risk children fram birth to adulthood. Ithaca, NY: ComeU University Press.

Wyman, P. A.; Cowen, E. L.; Work, W. c.; HoytMeyers, L. A.; Magnus, K. B. \& Fagen, D. B. (1999). Developmental and caregiving factors differentiating parents of young stress-affected and stress-resilient urban children: A replication and extension. Child Development, (ln Press).

Wyman, P. A.; Cowen, E. L.; Work, W. C. \& Parker, G. R. (1991). Developmental and family milieu interview correlates of resilience in urban children who have experienced major lifestress. American Journal ofCommunity h,ychology, 19,405-426.

Wyman, P. A.; Cowen, E. L.; Work, W. C.; Raoof, A.; Gribble, P. A.; Parker, G. R. \& Wannon, M. (1992). Interviews with children who experienced major life stress: Family and child attributes that predict resilient outcomes. Journal of the American Academy of Child and Adolescent Psychiatry, 31, 904-910.

Wyman, P. A.; Work, W. C.; Kerley, 1.; Hightower, A. D.; Cowen, E. L. \& Lotyczewski, B. S. Predicting substance abuse risk behaviors among inner-city adolescents from childhood competencies and family life-stress: A longitudinal study. (Submitted).

Y oshikawa, H. (1994). Prevention as cumulative protection: Effects of early family support and education on chronic delinquency and its risks. Psychological Bulletin, 115, 28-54.

Zigler, E.; Taussig, C. \& Black, K. (1992). Early childhood intervention: A promising preventative for juvenile delinquency. American Psychologist, 47, 997-1006. 